\title{
Enantioselective Arylative Trifluoromethylation of Alkenes
}

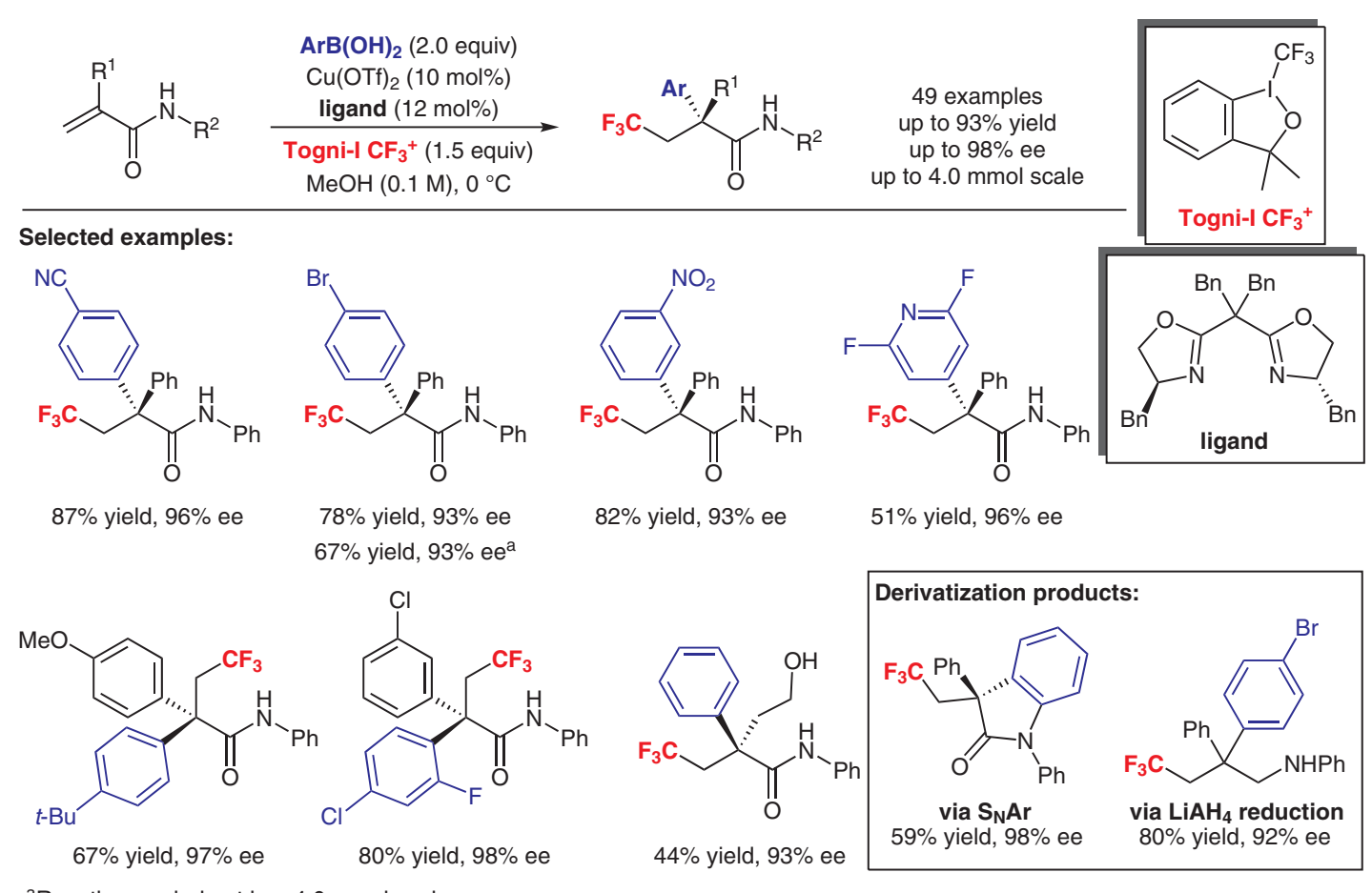

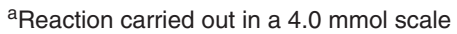

Radical trap experiment:

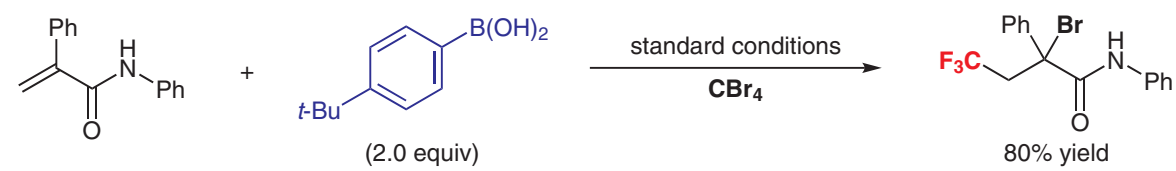

Significance: The asymmetric trapping of tertiary carbon-centered radicals represents a challenge in organic synthesis. The authors report an asymmetric coupling of tertiary radicals with $\mathrm{L}^{*} \mathrm{Cu}(\mathrm{II})$-aryl species for the synthesis of enantiomerically enriched quaternary carbons. The tertiary carboncentered radicals were generated via $\mathrm{CF}_{3}$ radical addition. The trifluoromethylated products were obtained in moderate to high yields, and good to high enantioselectivities.
Comment: The scalability of this process was determined on a $4.0 \mathrm{mmol}$ reaction, which provided the desired product with no erosion of enantioselectivity. Various derivatizations were performed on the trifluoromethylated products, such as cyclization (via nucleophilic aromatic substitution) and reduction of the carbonyl group. A radical trap experiment using $\mathrm{CBr}_{4}$ generates an $\alpha$-bromo amide in high yields, supporting the presence of benzylic radicals. 